\title{
Research Paper: \\ Effects of Aerobic Exercises on Patients With Coronary Artery Disease
}

\author{
Farhad Rahmani-Nia ${ }^{1,2}$ (D) Arash Layegh ${ }^{1^{*}}$ (D), Naser Aslanabadi ${ }^{3,4}$ (iD)
}

1. Department of Exercise Physiology, Faculty of Sport Sciences, University Campus 2, University of Guilan, Rasht, Iran.

2. Department of Exercise Physiology, Faculty of Sport Sciences, University of Guilan, Rasht, Iran.

3. Department of Cardiology, Faculty of Medicine, Tabriz University of Medical Sciences, Tabriz, Iran.

4. Cardiovascular Research Center, Tabriz University of Medical Sciences, Tabriz, Iran.

\section{(i) (3)}

Article info:

Received: 18 Aug 2019

Accepted: 25 Sep 2019

Available Online: 01 Jan 2020

Keywords:

Adrenergic beta-Antagonists, Aerobic training, Blood Glucose, Coronary Artery Disease, Lipoproteins
Rahmani-Nia F, Layegh A, Aslanabadi N. Effects of Aerobic Exercises on Patients With Coronary Artery Disease. Journal of Exercise Science and Medicine. 2020; 12(1):35-46. http://dx.doi.org/10.32598/JESM.12.1.4

http://dx.doi.org/10.32598/JESM.12.1.4

* Corresponding Author:

Arash Layegh, PhD.

Address: Department of Exercise Physiology, Faculty of Sport Sciences, University Campus 2, University of Guilan, Rasht, Iran.

Tel: +98 (914) 1076141

E-mail: alayeq@gmail.com 


\section{Introduction}

ardiovascular disease is the leading

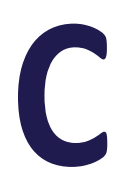
cause of death, globally. In 2019, approximately 55.4 million individuals died worldwide; of which, 15 million (about $27 \%$ percent) were induced by cardiovascular disease; nearly 8.9 million of them were concerned with ischemic heart disease alone [1].

Coronary Artery Disease (CAD) refers to conditions in which, the narrowing of the coronary arteries leads to decreased blood flow to the heart muscle [2]. The main cause of the cardiovascular disease is atherosclerosis. Some risk determinants were identified that may increase the risk of developing atherosclerosis. Mainly, they include high serum Total Cholesterol (TC), LowDensity Lipoprotein Cholesterol (LDL), and High-Density Lipoprotein Cholesterol (HDL), as well as hypertension, smoking, diabetes, obesity, and a sedentary lifestyle [3].

Aerobic exercise, a component of cardiac rehabilitation, is an essential treatment modality for reducing cardiovascular mortality in patients with CAD [4]. Aerobic exercise was demonstrated to improve the prognosis of Cardiovascular Disease (CVD). Compared to pharmacotherapy, aerobic exercise is easier to perform and has fewer adverse effects [5].

Multiple studies focused on the relationship between aerobic exercise and HDL. Accordingly, they found that HDL levels are more sensitive to aerobic exercise than LDL and Triglyceride (TG) levels [6-9]. Increased LDL concentrations were repeatedly identified to be associated with an increased risk of myocardial infarction and vascular death [10]. High-Density Lipoprotein (HDL) is a strong, consistent, and independent predictor of cardiovascular events, i.e., confirmed by numerous prospective studies on different racial and ethnic groups worldwide $[11,12]$ Decreasing serum cholesterol can help reduce the risk of CAD [13]. In addition, TG can enter the arterial wall and then accumulate there; thus, causing the possibility of atherosclerosis [14]. It is reported that exercise can induce lower plasma TG concentrations [6, 7].

Unlike HDL, the effect of exercise on LDL is inconsistent in individuals. There are even completely contrary results $[6,7]$. Some studies reported that aerobic exercise alone did not change the fasting blood LDL levels [9]. In some patients with mild to moderate dyslipidemia, the researchers found that after a few months of aerobic exercise, LDL did not change significantly [15].
Exercise can help improve lipids profile. Pedersen and Saltin concluded that exercise can positively impact symptoms and physical health by investigating multiple meta-analyses about exercise and lipid profiles [16].

Numerous factors lead to different results on the effects of aerobic exercise on lipoprotein levels, such as various training times or training intensities. Some researchers believe that to keep this effect longer, aerobic exercise time also needs to be longer; also, exercise intensity, time, and exercise volume influence exerciseinduced changes in blood lipids. To further reduce LDL and TG levels, it is necessary to increase the aerobic exercise intensity. However, this is difficult to achieve in individuals with CAD who are of limited exercise capacity or other risk factors $[6,9]$.

Exercise plays an essential role in reducing mortality and morbidity associated with cardiac rehabilitation programs due to its physiological effects on the body $[17,18]$. According to recent guidelines, beta-blockers are recommended as the first line of heart attack prevention regimens. Beta-Blockers reduce mortality and disease complications in individuals with hypertension, $C A D$, acute myocardial infarction, and heart failure [19].

Beta-Blockers are generally divided into two subgroups, as follows: cardio-selective beta blockers that possess a higher affinity for cardiac $\beta 1$-receptors than for $\beta 2$-receptors; and non-cardio-selective beta-blockers [20]. The effect of beta-blockers on the human body is inconsistent with the physiological effects of exercise. Beta-Blockers, reduce heart rate, heart contractile strength, and blood pressure; thus, they decline the myocardium's need for oxygen and improve chest pain. However, aerobic exercise, by increasing the need for oxygen and blood supply to active muscles, increases heart rate and blood pressure, during exercise [19]. A long-term administration of beta-blockers in some patients with the features of metabolic syndrome, could increase triglyceride levels and decrease high-density lipoprotein levels [21]. The antagonism of peripheral beta-adrenergic receptors is much less with the cardioselective beta-blockers. Besides, lower doses of these agents present negligible effects on lipoprotein parameters. Thus, for patients who require a beta-blocker, a cardio-selective agent may be preferred $[22,23]$.

Cardiac rehabilitation is mainly based on exercise prescribing. Besides, it is important to recognize how certain medications, like beta-blockers, affect patients' ability to perform an effective and safe exercise; then design exercise programs that meet the specific needs of pa- 
tients [24]. The effect of different types of beta-blockers on the patient's exercise program during cardiac rehabilitation is neglected in choosing the prescribed betablocker. Therefore, due to the widespread prescription of these medications in $C A D$, we intended to study the interaction effects of beta-blockers and aerobic training on FBS and lipid profile. We also separately compared them in selective versus non-selective beta-blockers between patients with CAD.

\section{Materials and Methods}

This was a quasi-experimental clinical trial. The population of the study included patients with CAD who were referred to the cardiac rehabilitation center of Shahid Madani Hospital in Tabriz City, Iran. Sampling was performed among the available and field samples of CAD patients who were treated with one of the drugs of two different types of beta-blockers (selective or nonselective) due to CAD. The study samples were entered into the research after fulfilling the basic conditions and obtaining informed consent.

The number of eligible patients who participated in the study included 62; of which, 25 subjects were taking non-selective beta-blockers (propranolol or carvedilol) and 37 were taking selective beta-blockers (atenolol or metoprolol). The gender distribution in the groups was to some extent similar. In the non-selective group, $79.2 \%$ and $20.8 \%$ of the subjects were male and female, in sequence. In the selective group, $69.4 \%$ were male and $30.6 \%$ were female. In the non-selective group, $50 \%$ of patients received propranolol and $50 \%$ carvedilol; in the selected group, $83.3 \%$ of patients used metoprolol, and $16.7 \%$ used atenolol. One of the patients in the nonselective group was excluded from the study due to the addition of digoxin to his treatment plan and the interaction of this drug with beta-blockers. Furthermore, one of the patients in the selective beta-blockers group could not continue to participate in the study due to lower limb problems. Therefore, in this study, 60 patients with CAD in two groups of selective $(n=36)$ versus non-selective $(n=24)$ beta-blocking agents were evaluated.

Sampling was performed among the available cases, which included almost all eligible cases. Patients entered the study after the inclusion criteria were met. Being in the low or moderate risk stratification, awareness of the research process by obtaining informed consent, and the ability to perform exercise was some of the inclusion criteria of the research. Moreover, the inability to exercise and using synergistic drugs or other medications that reduce the effect of beta-blockers were also some of the exclusion criteria of the study. Patients were gradually referred to the cardiac rehabilitation center; thus, the sampling and research process lasted approximately a year.

Contrary to the usual where old methods are used and not much attention is paid to new guidelines, the exercise protocol in this study was adjusted to ACSM's guidelines for exercise prescription and some other newer principles, including the following components $[7,25]$ :

According to the objectives of the study, the type of exercise for patients was continuous aerobic training, i.e., performed using a treadmill.

Three sessions of aerobic training were performed every other day per week, for 8 weeks.

Exercise intensity was determined by the Karvonen formula in the range of $40 \%$ to $60 \%$ of the reserved heart rate. When beta-blockers suppress heart rate, it is problematic to use the target heart rate (Karvonen equation) to measure the intensity of exercise. Therefore, we considered this point in calculating the maximum heart rate before calculating the target heart rate, by the following equations [17].

Maximum Heart Rate in CAD patients taking betablockers equation:

HR max=164-(0.7xAge)

Heart Rate Reserve equation:

HRR (Heart Rate Reserve)=HR max-HR rest

Target heart rate (Karvonen equation):

\section{Target $H R=(H R R \times \%$ Intensity $)+H R$ rest}

Each session lasted 20-45 minutes for the main stage of training (conditioning phase), excluding the time required for warming up, cooling down, and stretching, and lasted an average of 50 minutes.

Exercise progress was separately defined per patient based on their conditions. It depended on some factors, such as age, functional capacity, and health conditions. In patients with favorable appearance and general conditions, the main phase of their training was increased to 5 to 10 minutes for one to two weeks. The intensity of the exercise started from $40 \%$ of the reserve heart rate, and after the patient could complete the main phase of 
the training for 20 minutes without any problems, the intensity of the workload gradually increased to a maximum of $60 \%$ of the reserve heart rate.

Laboratory tests included Lipid Profile (HDL, LDL, total cholesterol, \& triglyceride) and FBS, i.e., performed once 48 hours before the start of the study and once after the end of the cardiac rehabilitation period; the results of the study were then statistically evaluated. The tests were performed taking by following the below considerations:

- The type of diet can affect the results of blood lipid tests; thus, the study subjects were requested to fast 12 hours before the test.

- During fasting, the study subjects avoided eating food and any snacks. Concurrently, they could drink the usual amount of water but avoid smoking, chewing gum, and exercising.

- The research subjects were requested to avoid eating high-fat foods for a week before taking blood samples.

- Blood samples were obtained from all examined patients at around 8 AM.

First, the Kolmogorov-Smirnov test was used to test the normality of the data. Since the distribution of research was normal, repeated-measures Analysis of Variance (ANOVA), Dependent Samples t-test, Independent Samples t-test, and Pearson correlation were used. The analyses were also performed in two sections; descriptive statistics and inferential statistics. In the part of the descriptive statistics, a general description of the research variables was presented and in the inferential statistics part, the distribution of the scores of variables was evaluated. Then, the study variables were compared in the selective and non-selective groups before and after the intervention. The significance level for the study was set at 5\%; therefore, the researchers attempted to be $95 \%$ sure of the study result, willing to accept the wrong result, $5 \%$ of the time.

\section{Results}

For all variables studied before and after the intervention and their changes, the mean and standard deviation values were calculated and reported in Table 1.

The Dependent Samples t-test was used to compare the mean values before and after the intervention in the non-selective group. The Dependent Samples t-test data are listed in Table 2. In the non-selective group, the mean FBS and TG levels significantly decreased after the intervention. The mean HDL, LDL, and TC levels did not change significantly.

Dependent Samples t-test was also used to compare the mean values of the variables before and after the intervention in the selective group. The Dependent Samples t-test results are provided in Table 3. Based on Table 3, in the selective group, none of the variables significantly changed after the intervention.

To compare the mean FBS levels before and after the intervention in the selective and non-selective groups, repeated-measures ANOVA was used. The ANOVA results indicated that the interactive effect of time and group on the FBS of the subjects at the $95 \%$ probability level was significant $(P=0.016$, Eta-squared $=0.10$, $\mathrm{F}=6.18$ ). In other words, the rate of FBS change of the subjects was significantly different before the intervention and after the intervention in the selective and non-selective groups. FBS loss was observed in the nonselective group, while an increase was observed in the selective group (Tables 4 and 5).

The relevant results suggested that the interactive effect of time and group was not significant on the HDL of the subjects at the $95 \%$ probability level $(P=0.58$, Eta-squared $=0.005, F=0.31$ ). In other words, the rate of change in the HDL of the subjects was not significantly different before the intervention and after the intervention in the selective and non-selective groups (Tables 6 and 7).

The obtained results revealed that the interactive effect of time and matched normal group was not significant on the LDL of the explored subjects at the $95 \%$ probability level ( $P=0.80$, Eta-squared $=0.001, F=0.06)$. In other words, the rate of change in the subjects' LDL did not significantly differ before the intervention and after the intervention in the selective and non-selective groups (Tables 8 and 9).

The collected results indicated that the interactive effect of time and matched normal group was not significant on the TG level of the subjects at the $95 \%$ probability level $(P=0.62$, Eta-squared=0.004, $F=0.24)$. In other words, the rate of change in the TG of the subjects was not significantly different before the intervention and after the intervention in the selective and non-selective groups (Tables 10 and 11). 
Table 1. Descriptive indices of the examined variables

\begin{tabular}{|c|c|c|c|c|c|c|}
\hline \multirow{3}{*}{ Variables } & \multicolumn{6}{|c|}{ Mean $\pm S D$} \\
\hline & \multicolumn{2}{|c|}{ Non-selective ß-blocker group } & \multicolumn{2}{|c|}{ Selective ß-blocker group } & \multicolumn{2}{|c|}{ Total } \\
\hline & Pretest & Posttest & Pretest & Posttest & Pretest & Posttest \\
\hline Age & $5.42 \pm 6.36$ & - & $56.44 \pm 7.67$ & - & $56.03 \pm 7.14$ & - \\
\hline Height & $169.83 \pm 6.98$ & - & $167.85 \pm 8.31$ & - & $168.64 \pm 7.81$ & - \\
\hline Weight & $83.62 \pm 9.38$ & $82.10 \pm 8.88$ & $79.51 \pm 7.84$ & $79.56 \pm 7.87$ & $81.15 \pm 8.66$ & $80.57 \pm 8.31$ \\
\hline BMI & $29.11 \pm 3.83$ & $28.60 \pm 3.88$ & $28.30 \pm 3.21$ & $28.30 \pm 3.17$ & $28.62 \pm 3.46$ & $28.42 \pm 3.44$ \\
\hline Waist circumstance & $98 / 02 \pm 4.77$ & $96.52 \pm 4.60$ & $97.89 \pm 6.30$ & $96.56 \pm 5.95$ & $97.94 \pm 5.69$ & $96.54 \pm 5.41$ \\
\hline Exercise capacity (MET) & $7.40 \pm 2.37$ & $10.27 \pm 2.28$ & $8.88 \pm 2.33$ & $10.03 \pm 2.69$ & $8.29 \pm 2.44$ & $10.13 \pm 2.52$ \\
\hline Weight difference & - & $-1.53 \pm 2.80$ & - & $0.05 \pm 0.79$ & - & $-0.58 \pm 2.01$ \\
\hline BMI difference & - & $-0.50 \pm 0.92$ & - & $0.00 \pm 0.27$ & - & $-0.20 \pm .066$ \\
\hline Waist circumstance difference & - & $-1.50 \pm 1.02$ & - & $-1.33 \pm 1.04$ & - & $-1.40 \pm 1.02$ \\
\hline Exercise capacity difference & - & $2.86 \pm 2.23$ & - & $1.16 \pm 2.75$ & - & $1.84 \pm 2.67$ \\
\hline
\end{tabular}

Exercise Science and Medicine

The achieved results demonstrated that the interactive effect of time and matched normal group on the TC of the subjects was not significant at the $95 \%$ probability level $(P=0.59$, Eta-squared $=0.005, F=0.29)$. In other words, the rate of change in the TC of the subjects before and after the intervention was not significantly different in the selective and non-selective groups (Tables 12 and 13).

\section{Discussion}

Table 2. Dependent samples t-test results to compare the Mean $\pm S D$ of the study variables before and after the intervention in the nonselective group

\begin{tabular}{|c|c|c|c|c|c|}
\hline Variables & Time & Mean $\pm S D$ & $\mathbf{t}$ & Degrees of freedom & Sig. \\
\hline Weight & $\begin{array}{l}\text { Before intervention } \\
\text { After intervention }\end{array}$ & $\begin{array}{l}83.62 \pm 9.38 \\
82.10 \pm 8.88\end{array}$ & 2.67 & 23 & 0.014 \\
\hline BMI & $\begin{array}{l}\text { Before intervention } \\
\text { After intervention }\end{array}$ & $\begin{array}{l}29.11 \pm 3.83 \\
28.60 \pm 3.88\end{array}$ & 2.68 & 23 & 0.013 \\
\hline Waist circumstance & $\begin{array}{l}\text { Before intervention } \\
\text { After intervention }\end{array}$ & $\begin{array}{l}98.02 \pm 4.77 \\
96.52 \pm 4.60\end{array}$ & 7.19 & 23 & 0.001 \\
\hline Exercise capacity & $\begin{array}{l}\text { Before intervention } \\
\text { After intervention }\end{array}$ & $\begin{array}{c}7.40 \pm 2.37 \\
10.27 \pm 2.28\end{array}$ & -6.30 & 23 & 0.001 \\
\hline
\end{tabular}


Table 3. Dependent Samples t-test results to compare the Mean $\pm S D$ of the variables before and after the intervention in the selective group

\begin{tabular}{|c|c|c|c|c|c|}
\hline Variables & Time & Mean $\pm S D$ & $\mathbf{t}$ & Degrees of freedom & Sig. \\
\hline Weight & $\begin{array}{l}\text { Before intervention } \\
\text { After intervention }\end{array}$ & $\begin{array}{l}79.51 \pm 7.84 \\
79.56 \pm 7.87\end{array}$ & -0.35 & 35 & 0.732 \\
\hline BMI & $\begin{array}{l}\text { Before intervention } \\
\text { After intervention }\end{array}$ & $\begin{array}{l}28.30 \pm 3.21 \\
28.30 \pm 3.17\end{array}$ & -0.04 & 35 & 0.966 \\
\hline Waist circumstance & $\begin{array}{l}\text { Before intervention } \\
\text { After intervention }\end{array}$ & $\begin{array}{l}97.89 \pm 6.30 \\
96.56 \pm 5.95\end{array}$ & 7.73 & 35 & 0.001 \\
\hline Exercise capacity & Before intervention & $8.88 \pm 2.33$ & -2.53 & 35 & 0.016 \\
\hline
\end{tabular}

Table 4. Box and Levin test results to examine the homogeneity of covariance matrix and FBS variance error

\begin{tabular}{cccccc}
\hline Variales & M Box & F & $\begin{array}{c}\text { Degrees of } \\
\text { freedom 1 }\end{array}$ & $\begin{array}{c}\text { Degrees of free- } \\
\text { dom 2 }\end{array}$ & Sig. \\
\cline { 2 - 6 } & $\mathbf{6 . 2 1 1}$ & $\mathbf{3 . 2 2 9}$ & $\mathbf{3}$ & $\mathbf{1 2 6 8 8 8 . 2 3 6}$ & $\mathbf{0 . 0 5 5}$ \\
\hline $\begin{array}{c}\text { Before interven- } \\
\text { tion }\end{array}$ & - & 1.365 & 1 & 58 & 0.247 \\
After intervention & - & 1.487 & 1 & 58 & 0.233 \\
\hline & & & & $\begin{array}{c}\text { Journal of } \\
\text { Ex }\end{array}$ \\
\hline
\end{tabular}

'ahmani-Nia, Tel: +98 $1333690260 \&$ +989113317344, Fax: lress: Frahmani2001@yahoo.com, [D: 0000-0001-7021-0060, !anabadi, Email address: aslanabadin@gmail.com, Mobile: +98 D: 0000-0003-2274-1494

Figure 1. FBS levels before and after intervention in the selective and non-selective groups 
Table 5. Results of repeated mixed ANOVA test to examine the effect of group and time on patient's FBS

\begin{tabular}{|c|c|c|c|c|c|c|}
\hline Source of change & Sum of squares & Degrees of freedom & Mean of squares & $\mathbf{F}$ & Sig. & Eta squared \\
\hline $\begin{array}{c}\text { Time effect } \\
\text { (before \& after) }\end{array}$ & 193.235 & 1 & 193.235 & 0.746 & 0.391 & 0.013 \\
\hline Group effect & 766.735 & 1 & 766.735 & 0.560 & 0.457 & 0.010 \\
\hline $\begin{array}{l}\text { Interactive effect if time } \\
\text { \& group }\end{array}$ & 15099.068 & 1 & 1599.068 & 6.176 & 0.016 & 0.096 \\
\hline Time error & 15016.632 & 58 & 258.907 & - & - & - \\
\hline Group error & 79343.132 & 58 & 1367.985 & - & - & - \\
\hline
\end{tabular}

Table 6. Box and Levin test results to investigate the homogeneity of covariance matrix and HDL variance error

\begin{tabular}{|c|c|c|c|c|c|}
\hline Variable & $\begin{array}{l}\text { M box } \\
1.138\end{array}$ & $\begin{array}{c}F \\
0.364\end{array}$ & $\begin{array}{c}\text { Degrees of freedom } 1 \\
3\end{array}$ & $\begin{array}{c}\text { Degrees of freedom } 2 \\
126888.236\end{array}$ & $\begin{array}{l}\text { Sig. } \\
0.779\end{array}$ \\
\hline Before intervention & - & 0.424 & 1 & 58 & 0.517 \\
\hline After intervention & - & 0.221 & 1 & 58 & 0.64 \\
\hline
\end{tabular}

ference in the levels of low-density and high-density lipoprotein cholesterol, compared to conventional care [27].

A large body of literature examined the effects of aerobic exercise on TC and triglyceride in some patients. Depending on the sample, time, intensity, frequency, a form of exercise, duration of randomized controlled trials, and different types of nutrition, the specific effects of aerobic exercise on patients' blood lipid levels may vary. Additionally, medications, like beta-blockers can affect glucose and lipid metabolism; they also differ in their mechanism of action and their effect on glucose and lipid metabolism based on differences in the type of beta-blockers [14]. The present study data indicated that in the non-selective group, the mean of the two variables FBS and triglyceride levels, significantly de- creased after the intervention. The mean values of $\mathrm{HDL}$, $\mathrm{LDL}$, and TC levels did not significantly change. However, in the selective group, none of the studied variables significantly changed. The findings of this study can be summarized as follows in Table 4:

The statistical comparison of research results between selective and non-selective groups reflected that the rate of changes was not significant in patients' TG and TC, before and after the intervention. Aerobic exercise in these two variables, especially in the non-selective group significantly decreased TG levels and was beneficial for both groups of patients; however, no significant difference was observed in the effects of aerobic exercise between the study groups. The rate of changes in HDL and LDL in individuals before and after the intervention was not sig-

Table 7. Results of repeated mixed ANOVA test to examine the effect of group and time on patient's HDL

\begin{tabular}{|c|c|c|c|c|c|c|}
\hline Source of change & Sum of squares & Degrees of freedom & Mean of squares & $\mathbf{F}$ & Sig. & Eta squared \\
\hline Time effect (before $\&$ after) & 104196 & 1 & 104196 & 3.668 & 0.060 & 0.059 \\
\hline Group effect & 14.535 & 1 & 14.535 & 0.111 & 0.740 & 0.002 \\
\hline Interactive effect of time $\&$ group & 8.778 & 1 & 8.778 & 0.309 & 0.580 & 0.005 \\
\hline Time error & 1647.795 & 58 & 28.410 & - & - & - \\
\hline Group error & 7578.183 & 58 & 130.658 & & & \\
\hline
\end{tabular}


per:

erobic Exercises on Patients With Coronary Artery Disease

$\cdot \mathrm{Nia}^{1,2}$, Arash Layegh $^{1 *}$, Naser Aslanabadi ${ }^{3,4}$

'Exercise Physiology Faculty of Sport Sciences, University Campus 2, University c

'Exercise Physiology, Faculty of Sport Sciences, University of Guilan, Rasht, Iran.

'Cardiology, Faculty of Medicine, Tabriz University of Medical Sciences, Tabriz, I

r Research Center, Tabriz University of Medical Sciences, Tabriz, Iran

Figure 2. HDL levels before and after intervention in the selective and non-selective groups

Exercise Science and Medicine

nificantly different in any of the selective and non-selective groups. In other words, the effect of aerobic exercise on LDL and HDL levels was not significant in the patients; the mean of these two variables was not significantly different in individuals after the intervention.

The present study findings indicated that the rate of FBS changes in individuals before and after the intervention was significantly different in the selective and non- selective groups. A decrease in FBS was observed in the group taking non-selective medications; however, in the group that took selective beta-blockers, it manifested no significant effect. Even a slight increase was observed in FBS. Therefore, the effect of aerobic exercise on FBS changes was more beneficial in CAD patients using nonselective beta-blockers, which reduced this cardiovascular risk factor. Therefore, using beta-blockers of both selective and non-selective types may neutralize some

\section{Ig Author}

Ph.D. in Exercise Physiology, Researcher

Alayeq@gmail.com, Mobile: +98 9141076141,

10-0002-3487-5994

Exercise Physiology, Faculty of Sport Sciences, University Campus 2

ran 
of the positive effects of aerobic exercise observed in previous studies. Non-Selective beta-blockers, especially carvedilol, are lipophilic; however, selective beta-blockers, especially atenolol, are hydrophilic. Accordingly, non-selective beta-blockers with higher fat solubility have a higher volume of distribution and hepatic firstpass effect and may have more central effects due to their greater entry into the central nervous system [19, $20,28]$.

Furthermore, drug binding to plasma proteins in nonselective beta-blockers is much greater than that in selective beta-blockers [5]. As a result, exercise-active muscles have greater access to non-selective beta-blockers, especially carvedilol, which also present vasodilatory effects. This is probably why the positive effects of aerobic exercise were greater in patients using non-selective beta-blockers. Selective beta-blockers, such as atenolol and metoprolol are non-vasodilating and decrease blood pressure, as they reduce cardiac output and may increase or have no significant effect on peripheral vascular resistance. Consequently, these beta-blockers are associated with exacerbating glycemic and lipid control [14].

Very few cardiac patients were referred to cardiac rehabilitation centers; therefore, the size of the study population was small. Consequently, the researchers selected almost the entire population as a sample. Subsequently, the study sample size was restricted. Another limitation of this study was the lack of complete control of patients' nutrition despite providing the same nutritional recommendations to all of them, because differences in the type of nutrition may affect laboratory results [3].

The widespread introduction of various pharmacotherapies, as part of the routine management of cardiac patient therapies, may offset the magnitude of benefit associated with exercise-based rehabilitation. An argument put forward against the primary use of betablockers has been concerned about adverse metabolic effects, like unfavorable effects on lipids or insulin sensitivity [29]. Moreover, selective beta-blockers are indicated for patients with asthma, or diabetes, in whom ß2receptor antagonism might associate with an increased risk of adverse effects [28]. Furthermore, based on the results of a review article conducted in 2013 by Ladage et al. [30], as well as a clinical trial conducted in 1990 by Ades PA et al. [31], it was suggested that selective beta-blockers might be preferred to non-selective betablockers in cardiac patients involved in the exercise.

\section{Conclusion}

The present findings of this study did not support these recommendations. Based on the research data, we concluded that the positive effects of aerobic exercise in reducing FBS and TG levels in patients with CAD who used non-selective beta-blockers were greater than the selective beta-blocker group. Aerobic exercise did not significantly improve lipid profile and FBS levels in patients taking selective beta-blockers; however, it had a more positive effect on those taking non-selective beta-blockers. Therefore, it is generally recommended that using non-selective beta-blockers may be preferred in patients with CAD who participate in aerobic exercisebased cardiac rehabilitation programs to benefit more from the positive effects of aerobic exercise.

\section{Ethical Considerations}

\section{Compliance with ethical guidelines}

All procedures of the project were carried out per ethical principles and the national norms and standards for conducting medical research in Iran and approved by the ethical committee for medical research. This study is under the support of Guilan University's Medical Research Ethics Committee (Code: IR.GUMS.REC.1398.061).

\section{Funding}

The paper was extracted from the PhD dissertation of the first author and financially supported by Department of Exercise Physiology, University Campus 2, University of Guilan.

\section{Authors' contributions}

Supervising review \& editing: Farhad Rahmani-Nia; Methodology, writing - original draft preparation: Arash Layegh; Data collection and Data analysis: Naser Aslanabadi. 


\section{Conflict of interest}

The authors declared no conflicts of interest.

\section{Acknowledgments}

The authors would like to thank Tabriz University of Medical Sciences for supporting this research.

\section{References}

[1] Ades PA, Gunther PG, Meyer WL, Gibson TC, Maddalena J, Orfeo T. Cardiac and skeletal muscle adaptations to training in systemic hypertension and effect of beta blockade (metoprolol or propranolol). The American Journal of Cardiology. 1990; 66(5):591-6. [DOI:10.1016/0002-9149(90)90486-K][PMID]

[2] Anderson JL, Adams CD, Antman EM, Bridges CR, Califf RM, Casey Jr DE, et al. 2012 ACCF/AHA focused update incorporated into the ACCF/AHA 2007 guidelines for the management of patients with unstable angina/non-ST-elevation myocardial infarction: A report of the American College of Cardiology Foundation/American Heart Association Task Force on Practice Guidelines. Journal of the American College of Cardiology. 2013; 61(23):e179-347. [DOI:10.1016/j. jacc.2013.01.014] [PMID]

[3] Balady GJ, Ades PA, Bittner VA, Franklin BA, Gordon NF, Thomas RJ, et al. Referral, enrollment, and delivery of cardiac rehabilitation/secondary prevention programs at clinical centers and beyond: A presidential advisory from the American Heart Association. Circulation. 2011 124(25):2951-60. [DOI:10.1161/CIR.0b013e31823b21e2] [PMID]

[4] Bangalore S, Messerli FH. Beta-blockers as fourth-line therapy for hypertension: Stay the course. International Journal of Clinical Practice. 2008; 62(11):1643-6. [DOI:10.1111/j.17421241.2008.01916.x] [PMID]

[5] Chobanian AV, Bakris GL, Black HR, Cushman WC, Green LA, Izzo $\mathrm{JL} \mathrm{Jr}$, et al. Seventh report of the Joint National Committee on Prevention, Detection, Evaluation, and Treatment of High Blood Pressure. Hypertension. 2003; 42(6):1206-52. [DOI:10.1161/01. HYP.0000107251.49515.c2] [PMID]

[6] Cholesterol Treatment Trialists' (CTT) Collaboration, Baigent C, Blackwell L, Emberson J, Holland LE, Reith C, et al. Efficacy and safety of more intensive lowering of LDL cholesterol: A meta-analysis of data from 170,000 participants in 26 randomised trials. Lancet. 2010; 376(9753):1670-81. [DOI:10.1016/S0140-6736(10)61350-5]

[7] do Vale GT, Ceron CS, Gonzaga NA, Simplicio JA, Padovan JC. Three generations of $\beta$-blockers: History, class differences and clinical applicability. Current Hypertension Reviews. 2019; 15(1):22-31. [DOI: 10.2174/1573402114666180918102735] [PMID]

[8] Foerster EC, Greminger P, Siegenthaler W, Vetter H, Vetter W. Comparison between atenolol and pindolol in essential hypertension. In: Schettler G, Assmann G, Diehm C, Moerchel J, editors. Betablocker und Lipidstoffwechsel. Heidelberg: Springer; 1984. [DOI:10.1007/978-3-642-69675-6_17]
[9] Fonseca VA. Effects of beta-blockers on glucose and lipid metabolism. Current Medical Research and Opinion. 2010; 26(3):615-29. [DOI:10.1185/03007990903533681] [PMID]

[10] Gibson AL, Wagner DR, Heyward VH. Advanced fitness assessment and exercise prescription. 8th ed. Champaign: Human Kinetics Press; 2018. https://books.google.com/books?id=FjxnDwAAQBAJ\&dq

[11] Goff Jr DC, Lloyd-Jones DM, Bennett G, Coady S, D'Agostino RB, Gibbons R, et al. 2013 ACC/AHA guideline on the assessment of cardiovascular risk: A report of the American College of Cardiology/American Heart Association Task Force on Practice Guidelines. Circulation. 2014; 129(25 Suppl 2):S49-73. [DOI:10.1161/01. cir.0000437741.48606.98] [PMID]

[12] Hansen D, Dendale P, Berger J, Meeusen R. Rehabilitation in cardiac patients: What do we know about training modalities? Sports Medicine. 2005; 35(12):1063-84. [DOI:10.2165/00007256200535120-00005] [PMID]

[13] Anderson L, Thompson DR, Oldridge N, Zwisler AD, Rees K, Martin $\mathrm{N}$, et al. Exercise-based cardiac rehabilitation for coronary heart disease. The Cochrane Database of Systematic Reviews. 2016; 2016(1):CD001800. [DOI:10.1002/14651858.CD001800.pub3] [PMID] [PMCID]

[14] Kraus WE, Houmard JA, Duscha BD, Knetzger KJ, Wharton MB, McCartney JS, et al. Effects of the amount and intensity of exercise on plasma lipoproteins. The New England Journal of Medicine. 2002; 347(19):1483-92. [DOI:10.1056/NEJMoa020194] [PMID]

[15] Ladage D, Schwinger RH, Brixius K. Cardio-selective beta-blocker: Pharmacological evidence and their influence on exercise capacity. Cardiovascular Therapeutics. 2013; 31(2):76-83. [DOI:10.1111/ j.1755-5922.2011.00306.x] [PMID]

[16] LeMura LM, von Duvillard SP, Andreacci J, Klebez JM, Chelland SA, Russo J. Lipid and lipoprotein profiles, cardiovascular fitness, body composition, and diet during and after resistance, aerobic and combination training in young women. European Journal of Applied Physiology. 2000; 82(5-6):451-8. [DOI:10.1007/s004210000234] [PMID]

[17] Lewington S, Whitlock G, Clarke R, Sherliker P, Emberson J, Halsey J, et al. Blood cholesterol and vascular mortality by age, sex, and blood pressure: A meta-analysis of individual data from 61 prospective studies with 55,000 vascular deaths. Lancet. 2007; 370(9602):1829-39. [DOI:10.1016/S0140-6736(07)61778-4]

[18] American College of Sports Medicine. ACSM's guidelines for exercise testing and prescription. Philadelphia: Wolters Kluwer; 2018. https://books.google.com/books?id=m_L-jwEACAAJ\&dq

[19] Nordestgaard BG, Wootton R, Lewis B. Selective retention of VLDL, ODL, and LDL in the arterial intima of genetically hyperlipidemic rabbits in vivo. Molecular size as a determinant of fractional loss from the intima-inner media. Arteriosclerosis, Thrombosis, and Vascular Biology. 1995; 15(4):534-42. [DOI:10.1161/01. ATV.15.4.534] [PMID]

[20] Nybo L, Sundstrup E, Jakobsen MD, Mohr M, Hornstrup T, Simonsen $L$, et al. High-intensity training versus traditional exercise interventions for promoting health. Medicine and Science in Sports and Exercise. 2010; 42(10):1951-8. [DOI:10.1249/ MSS.0b013e3181d99203] [PMID]

[21] O'Donovan G, Owen A, Bird SR, Kearney EM, Nevill AM, Jones $D W$, et al. Changes in cardiorespiratory fitness and coronary heart disease risk factors following $24 \mathrm{wk}$ of moderate- or high-intensity exercise of equal energy cost. Journal of Applied Physiology. 2005 98(5):1619-25. [DOI:10.1152/japplphysiol.01310.2004] [PMID] 
[22] Ong HT. Beta blockers in hypertension and cardiovascular disease. BMJ 2007; 334(7600):946-9. [DOI:10.1136/bmj.39185.440382.47] [PMID] [PMCID]

[23] Pedersen B, Saltin B. Evidence for prescribing exercise as therapy in chronic disease. Scandinavian Journal of Medicine \& Science in Sports. 2006; 16(Suppl 1):3-63. [DOI:10.1111/j.16000838.2006.00520.x] [PMID]

[24] American College of Sports Medicine. ACSM's advanced exercise physiology. 2nd ed. Philadelphia: Lippincott Williams \& Wilkins Press; 2012. https://books.google.com/books?id=MHiicQAACAAJ\&dq

[25] Sharma AM, Pischon T, Hardt S, Kunz I, Luft FC. Hypothesis: Beta-adrenergic receptor blockers and weight gain: A systematic analysis. Hypertension. 2001; 37(2):250-4. [DOI:10.1161/01.HYP.37.2.250] [PMID]

[26] Taylor RS, Brown A, Ebrahim S, Jolliffe J, Noorani H, Rees K, et al. Exercise-based rehabilitation for patients with coronary heart disease: Systematic review and meta-analysis of randomized controlled trials. The American Journal of Medicine. 2004; 116(10):682-92. [DOI:10.1016/j.amjmed.2004.01.009] [PMID]

[27] World Health Organization (WHO). The top 10 causes of death [Internet]. 2020 [Updated 2020 December 9]. Available from: https://www. who.int/news-room/fact-sheets/detail/the-top-10-causes-of-death

[28] Torres N, Guevara-Cruz M, Velázquez-Villegas LA, Tovar AR. Nutrition and atherosclerosis. Archives of Medical Research. 2015; 46(5):408-26. [DOI:10.1016/j.arcmed.2015.05.010] [PMID]

[29] Toth PP, Barter PJ, Rosenson RS, Boden WE, Chapman MJ, Cuchel $M$, et al. High-density lipoproteins: A consensus statement from the National Lipid Association. Journal of Clinical Lipidology. 2013; 7(5):484-525. [DOI:10.1016/j.jacl.2013.08.001] [PMID]

[30] Varady KA, St-Pierre AC, Lamarche B, Jones PJ. Effect of plant sterols and endurance training on LDL particle size and distribution in previously sedentary hypercholesterolemic adults. European Journal of Clinical Nutrition. 2005; 59(4):518-25. [DOI:10.1038/ sj.ejcn.1602106] [PMID]

[31] Weir MR, Moser M. Diuretics and beta-blockers: Is there a risk for dyslipidemia? American Heart Journal. 2000; 139(1 Pt 1):174-84. [DOI:10.1016/S0002-8703(00)90325-9] 
Winter \& Spring 2020, Volume 12, Number 1

Exercise Science and Medicine

46 